\title{
LA FOTOGRAFÍA COMO ESTANDARTE DE LA VERDAD Y EL PROGRESO: ESTUDIO SOBRE LA ICONOGRAFÍA FOTOGRÁFICA EN LA MEDALLÍSTICA (1880-1920)
}

\section{TRUTH AND PROGRESS: THE ICONOGRAPHY OF PHOTOGRAPHY IN MEDAL ART (1880-1920)}

\section{Jorge L. Crespo Armáiz}

SUAGM San Juan, Puerto Rico

\section{Resumen:}

Desde el momento de su creación a mediados del siglo XIX, la invención fotográfica representó un cambio profundo en la mentalidad de la sociedad decimonónica en lo relativo a su impacto en la reproducción y diseminación de las imágenes visuales. Durante las primeras décadas siguientes a su invención, los entusiastas de la fotografía propulsaron un discurso de superioridad mimética de la misma por sobre las artes visuales tradicionales, sobre la base de la supuesta objetividad absoluta de su registro ópticoquímico. La fuerza de esta mentalidad discursiva del nuevo paradigma visual se reflejó en la literatura y demás expresiones culturales, incluyendo las propias artes plásticas. A través de un análisis iconográfico de un conjunto de medallas del período se pueden identificar los signos, códigos y discursos relativos a la fotografía como reflejo de las mentalidades positivistas imperantes de la época.

\begin{abstract}
:
Since its invention in the first half of the nineteenth century, photography represented a profound change in the mentality of European society regarding its impact in the reproduction and dissemination of visual images. During its initial developmental stage, fanatics of the new medium gave impulse to a discourse of mimetic superiority of photography over traditional visual arts, based upon the alleged absolute objectivity of its optical-chemical registry. This discursive mentality reflected its influence in literature, as well as in other cultural expressions, including the visual arts. Through the implementation of an iconographic analysis of a sample of award and commemorative medals of this period, this article looks to identify those signs, codes and discourses related to photography as symbol of progress and absolute truth within the positivism paradigm.
\end{abstract}

\section{Palabras clave:}

Fotografía; medallística; iconografía; imágenes visuales; mentalidades

\section{Keywords:}

Photography; iconography; medallic art; visual images; mentalities 


\section{Impacto cultural de la invención fotográfica}

Desde su presentación oficial en la Academia de las Ciencias en París en 1839, la invención del proceso fotográfico marcó un impacto sin precedentes en las convenciones y mentalidades de las sociedades europeas con respecto a la representación y reproducción de las imágenes visuales. Casi de inmediato emergió un fuerte debate entre los defensores de las bellas artes tradicionales -en particular la pintura- y los fanáticos de la alegada perfección y veracidad del proceso fotográfico. El foco esencial de este debate giraba alrededor del aspecto del realismo, de la capacidad de representación analógica del nuevo medio, de su poder de copiar con mayor o menor similitud aquello que pretende representar.

En el caso de los medios de representación visual derivados de las artes plásticas (como la pintura, la escultura o el grabado), el problema de los niveles de analogía o similitud y su impacto en la percepción de realismo es crítico, dado que las destrezas artísticas, el dominio de las técnicas y estilos (que varían de época en época), los conocimientos científicos y anatómicos, y muchos otros factores incidirán con muy diversos grados en la "verosimilitud" que el espectador habrá de adjudicar a la representación en cuestión. Por ello, al tratarse de las artes plásticas siempre se había permitido mayor flexibilidad y subjetividad en la valoración y aceptación de las imágenes como modelos de la realidad. Se daba por entendido que el artista, a más de sus destrezas técnicas, podía aplicar su creatividad e inspiración subjetiva a la obra producida. No obstante, la invención del proceso fotográfico a mediados del siglo XIX provocó la prevalencia de toda una nueva perspectiva sobre la verosimilitud visual. Los desarrollos de Joseph Nicéphore Niépce, Louis Daguerre, Henry Fox Talbot y otros pioneros abrieron un nuevo paradigma sobre lo visual. La nueva invención suponía la superación de la ambigüedad y el subjetivismo de las artes plásticas por la capacidad, no ya de elaborar representaciones similares o análogas, sino réplicas, copias exactas de la realidad. Al igual que ocurrió en otros órdenes sociales y económicos tras la revolución industrial, la fotografía aportaba la "rigurosidad científica" de un proceso químico/óptico que 
garantizaba la documentación a perpetuidad de las imágenes de personas, paisajes y sucesos.

Según expresa Martine Joly (1994: 73), la fotografía se consideró como una imitación perfecta de la realidad. Esto, debido a la técnica misma, a su procedimiento mecánico, que permitía aparecer una imagen de manera "automática”, “objetiva”, casi "mágica”, contando tan solo con las leyes de la óptica y de la química, sin la intervención directa de la mano del artista, en su concepción tradicional. Es útil recordar en este punto, el origen etimológico de la palabra "fotografía”, esto es, "escritura de la luz"; enfatizando que la imagen no era otra cosa que el producto de un proceso foto-químico, que "garantizaba" que ésta era literalmente un fiel reflejo del referente original. Gabriel Bauret (1992: 48) expande la profundidad de esta concepción, al aseverar que "el procedimiento [fotográfico] aparecía más fiable [que la pintura] desde un punto de vista científico, respecto de un modo de representación manual, y por tanto como más seguro. Esta convicción explica el por qué la mayoría cree que lo que muestra la fotografía no puede someterse a discusión, que este tipo de documento certifica la verdad de los hechos. «Fue así»" (notas y énfasis nuestro).

Comenzó de esta forma la primera gran etapa de la historia cultural de la fotografía, la cual podemos identificar como el denominado discurso de la "fotografía-espejo" o la exaltación del poder mimético del nuevo medio. Este paradigma, el cual postulaba la incuestionable perfección y veracidad de lo fotografiado -en cuanto reflejo objetivo del referente, sin intervención del ser humano- persistirá hasta bien entrado el siglo XX y tendrá repercusiones profundas en los efectos de las imágenes fotográficas sobre la creación, difusión e interpretación de contenidos hacia sus distintos públicos y consumidores a través del tiempo. La fotografía como espejo fue considerada masivamente como una imitación perfecta de la realidad -lo que Roland Barthes (1961) denominará un siglo más tarde como su "analogón”.

Aunque los rezagos de este discurso de superioridad mimética persisten hasta nuestros días, ya desde mediados del siglo XX la crítica semiótica contribuyó significativamente a deconstruir dicha mentalidad discursiva, 
haciéndonos conscientes de los múltiples y variados niveles de connotación, códigos y mensajes culturales que pueden esconderse tras el alegado registro objetivo de la imagen fotográfica. Sabemos hoy con toda certeza que, más allá de su incuestionable valor como documento y registro de la realidad, la fotografía es sobre todo un artefacto y producto cultural. Más allá de lo denotado en su registro, el documento fotográfico encierra y comunica mensajes connotados derivados de los valores y bagaje cultural de su autor (el fotógrafo), de las intervenciones en los procesos de edición, reproducción y distribución, y finalmente, de la propia interpretación que nosotros le adscribimos como espectadores, producto de nuestros propios valores y visión de mundo.

No es nuestra intención en este trabajo profundizar o abundar en la evolución histórica de los discursos relativos a la fotografía como documento y artefacto cultural. Ello amerita mucho más espacio y atención que la que aquí le podemos dedicar. Nuestro interés particular es examinar la forma en que la mentalidad derivada del discurso mimético de la fotografía, así como su rol protagónico dentro del discurso de progreso y la modernidad, se reflejan de forma patente en otras manifestaciones artísticas y culturales, y muy en particular en el caso del diseño y emisión de medallas conmemorativas.

\section{Las medallas de tema fotográfico}

A medida que la invención y práctica del proceso fotográfico se fue difundiendo, la popularidad de la fotografía - primero como oficio y luego como afición - se extendió por toda Europa. Rápidamente surgieron sociedades y clubes de aficionados al nuevo medio en casi todas las principales ciudades europeas, pero principalmente en Francia e Inglaterra. Estas entidades desarrollaron competencias y exhibiciones anuales, comisionando y otorgando medallas especiales de premiación para reconocer los logros técnicos y artísticos de los participantes. Muchas de estas medallas son, por lo general, de hermoso diseño, destacándose los estilos victorianos de finales de siglo XIX, así como los estilos del "art nouveau” y el "art deco" 
de inicios de siglo XX. Es imperativo aquí hacer un alto para describir y definir con precisión el objeto material de nuestra atención. A diferencia de la moneda de curso legal, la medalla es una pieza fundida o acuñada que no lleva indicación de valor, no forma parte de ninguna serie, ni es emitida por disposición gubernativa, salvo en casos muy especiales. Es de forma y materia variable $\mathrm{y}$ su propósito es esencialmente conmemorativo, recordatorio, artístico o como objeto de premiación (Burzio, 1958: 44).

En esencia, una medalla es una pieza escultórica, solo que en su caso se limita a un tamaño reducido y a un formato de relieve sobre una superficie plana de poco espesor, sea ésta por lo general redonda, cuadrada o de otra forma variable. Como pieza escultórica al fin, la medalla debe considerarse como un objeto artístico. De hecho, en su mayoría los principales escultores del pasado y del presente han trabajado la medalla como medio de expresión artística, ya sea por comisión o por iniciativa personal. Siendo un medio de expresión artística, las medallas, al igual que la pintura o la escultura, sirven para reflejar, no solo las convenciones y estilos artísticos, sino también la visión de mundo, los valores, las creencias y prejuicios, no solo del artista que la diseña y produce, sino también de aquellos que las comisionan. Como cualquier obra de arte, documento o artefacto cultural (similar a la fotografía), la medalla es un reflejo material de los estilos, valores y mentalidades de la época, así como del contexto socio-cultural en que son creadas.

Las medallas "fotográficas" o relativas a la fotografía (esto es, cuyo tema central es la fotografía como proceso, disciplina, oficio o afición), y principalmente aquellas emitidas durante el período de auge del nuevo medio, se caracterizan por la utilización de una serie de elementos icónicos particulares. En muchos casos estos elementos visuales van más allá de un mero accesorio decorativo, sino que constituyen imágenes simbólicas o signos de clara carga valorativa. Un examen de un número variado de medallas de tema fotográfico, producidas entre 1880 hasta mediados del primer tercio del siglo XX, presenta consistencia en la utilización de estos elementos los cuales, más allá de su significado primario o convencional, 
constituyen elementos discursivos dirigidos a exaltar una serie de atributos de la fotografía bien acendrados en la mentalidad decimonónica. Entre estos recursos icónico-discursivos podemos destacar:

- la supremacía de la fotografía como réplica de la realidad y emisaria de la verdad

- la identificación de la fotografía con las bellas artes

- la fotografía como símbolo del avance científico, el progreso y la modernidad.

\section{Iconografía de las medallas fotográficas}

$\mathrm{Al}$ abordar el análisis de los elementos y posibles significados de las medallas, así como de cualquier otra clase de obra artística de carácter visual, resulta sumamente beneficiosa la aplicación de los conceptos de iconografía e iconología, desarrollados desde mediados del pasado siglo por el estudioso y crítico de arte, Erwin Panofsky (1980). Los conceptos iconográfico e iconológico tienen estrecha relación con los elementos de denotación y connotación ya expuestos, respectivamente. Los primeros vienen a constituir los procesos de análisis para estudiar y descomponer los segundos.

La iconografía nos propone el proceso de descomponer y describir los elementos visuales que integran la imagen; esto es lo denotado. En contraposición, el análisis iconológico es el que nos lleva a reconocer y, si posible, interpretar los significados, códigos o connotaciones simbólicas que derivan directamente de la imagen iconográfica, o que subyacen a esta. De los trabajos de Panofsky se establece la existencia de al menos tres (3) niveles de significado en toda imagen visual, sea esta una pintura, una escultura, una fotografía, o en nuestro caso, una medalla:

- Descripción pre-iconográfica: Consiste de una simple enumeración de los elementos visuales que componen la escena (objetos, personas, paisaje). Es todo aquello material que está allí, frente a nosotros y que, de forma aislada, podemos describir e identificar sin adscribirle necesariamente un valor simbólico alguno (una palmera, una mesa, una colina, un soldado). Podríamos decir que son los elementos literales, denotados. 
- Descripción iconográfica: Sería un reconocimiento ya formal del significado "convencional", típico o generalizado que la imagen nos brinda en la conjunción ya integrada de todos sus elementos. El conjunto de elementos nos puede presentar un evento familiar, un incidente político particular, una escena campestre, o la ejecución de un prisionero. Esta descripción iconográfica ya no es denotación pura, pues puede responder a diversas perspectivas e interpretaciones, ya personales del espectador, o incluso dirigidas por el productor o presentador de la imagen.

- Descripción iconológica: Este nivel centra su atención en el significado o significados intrínsecos de la imagen, aquellos códigos, símbolos, o discursos subyacentes a la misma. El evento familiar puede querer trasmitir valores sobre la importancia de la familia (o lo contrario), la escena campestre puede connotar los valores de una vida rural ya desaparecida (o la conservación de los recursos naturales), la ejecución del prisionero puede plantear un apoyo discursivo sobre la lucha contra la pena de muerte (o bien todo lo contrario, refrendar el poder de castigo del estado en advertencia al delincuente).

Estos tres niveles de significado también se identifican, de forma más simple, como análisis literal, histórico y cultural, respectivamente, o como expresa el propio Panofsky (1980: 57), se trata del análisis de las "formas” visuales, los "temas" o tipos y, finalmente, los signos o "síntomas" culturales detrás de dichas formas y temas. Sin duda alguna el nivel de análisis iconológico o cultural es el más difícil, pues se trata de connotación pura, tanto la que pueda estar imbuida en la imagen como la que nosotros le adscribamos por efecto de nuestras propias cargas culturales y convenciones. Utilizando de referencia metodológica estos conceptos y niveles de análisis de las imágenes visuales, procedamos a considerar un conjunto de medallas conmemorativas relativas a la fotografía con el propósito de identificar, tanto su construcción iconográfica como los posibles mensajes codificados o elementos discursivos iconológicos contenidos en las mismas.

En primer término, desde sus inicios uno de los elementos visuales preiconográficos más comunes en este tipo de medallas -como es de esperarsees la reproducción de la imagen de la cámara fotográfica. Derivada de la 
evolución del antiguo concepto de la "cámara oscura”, la cámara fotográfica constituyó la invención cumbre que unía los procesos ópticos, mecánicos y químicos para hacer posible el registro de los referentes del mundo real. La imagen de la cámara fotográfica como artefacto e invención aparece resaltada en infinidad de medallas del período bajo estudio. En muchas ocasiones la cámara fotográfica aparece acompañada por figuras alegóricas o mitológicas (femeninas en su mayoría), figuras aladas (cupidos, ángeles), coronas y ramas de olivos o laureles, todos símbolos ampliamente reconocidos de apoteosis, homenaje o exaltación.
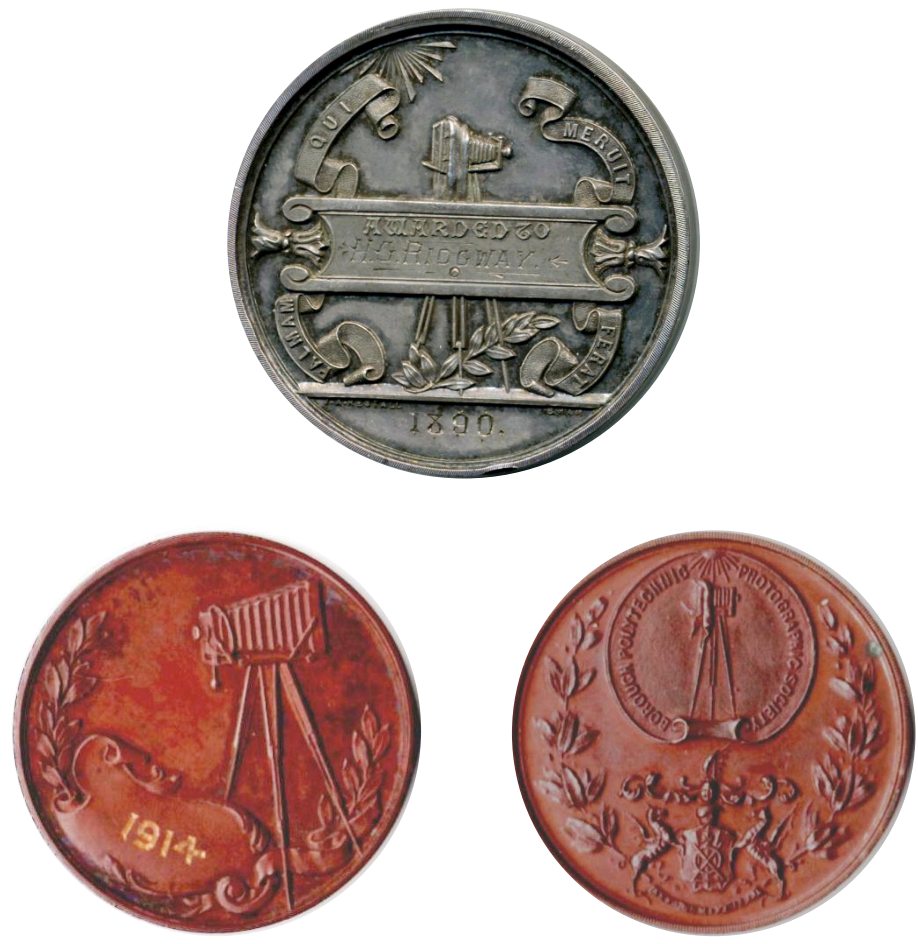

Arriba: NEWCASTLE PHOTOG. ASSOCIATION (1890), plata, 46mm; Izquierda: BOROUGH POLYTECHNIC PHOTOGRAPHIC SOCIETY (1913), cobre, 45mm; Derecha: ROTHERHAM PHOTOGRAPHIC SOCIETY (1914), cobre, 39mm. Colección del autor.
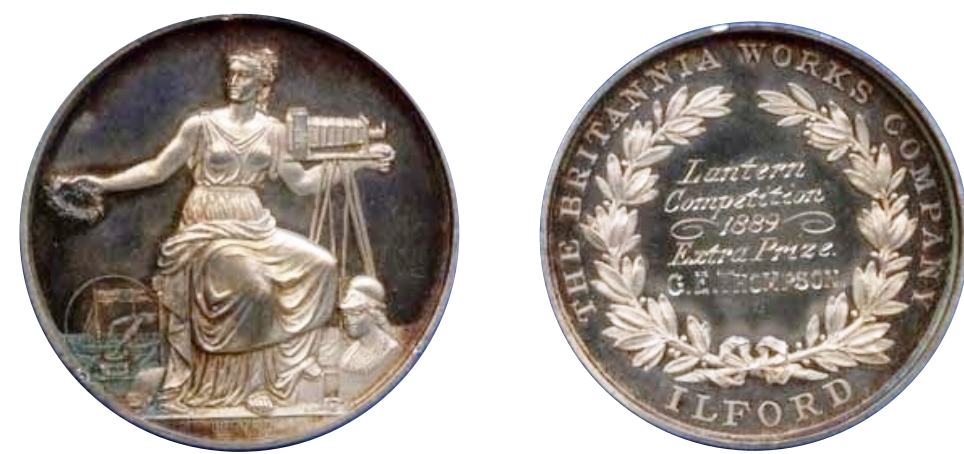

130 
THE BRITANNIA WORKS COMPANY (1889), plata, 51mm. Figura alegórica femenina, sujetando una corona de laureles y la cámara fotográfica. Al pie un busto de Atenea, símbolo de la sabiduría. Colección del autor.
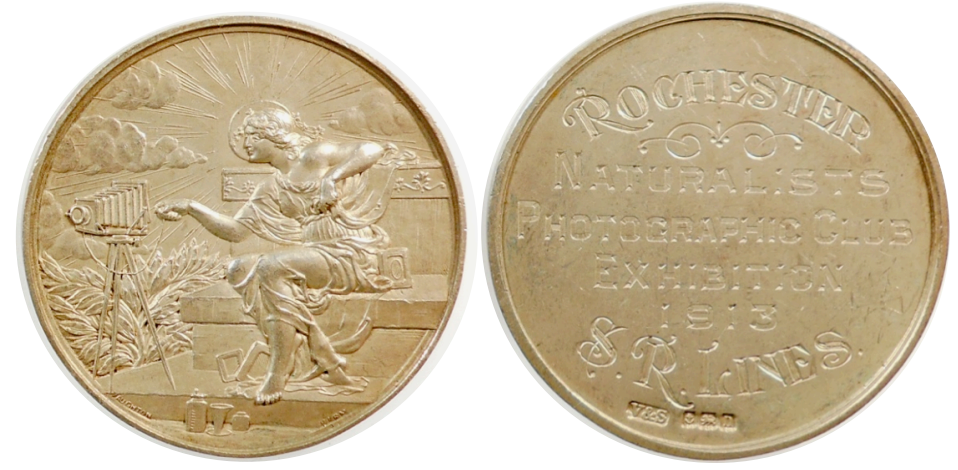

ROCHESTER NATURALISTS PHOTOGRAPHIC CLUB (1913), latón, 45mm.

Vaughton \& Sons, Birmingham. Colección del autor

En el caso de esta medalla del ROCHESTER NATURALISTS PHOTOGRAPHIC CLUB, obsérvese la centralización de la cabeza sobre el disco solar, formando un halo de luz que aparenta surgir del rostro. Este efecto deifica la figura femenina, colocándola a un nivel superior del ser humano convencional. Existen dos posibles interpretaciones de esta simbología. En primer término, la figura femenina puede representar la propia luz solar, elemento esencial del proceso fotográfico (la "escritura de la luz”), sin la cual no sería posible el registro de la naturaleza y los objetos en el proceso químico-óptico. Por otro lado, podría representar la propia naturaleza, la cual, nuevamente, se reproducía a sí misma, por medio de la luz, a través del proceso fotográfico. Un examen más detenido revela que la mujer presenta una diadema con una diminuta estrella sobre su frente, elemento que refuerza su naturaleza divina o sobrenatural. Se trata de un cuadro claramente alegórico de exaltación del nuevo paradigma que postula la reproducción de la propia naturaleza a través del proceso fotográfico, sin intervención del artista o el ser humano.

La simbología relativa a la supremacía mimética y a la capacidad de la naturaleza para reproducirse a sí misma a través del proceso científico que representaba la invención fotográfica se repite en este tipo de medallas, como lo vemos con claridad en la construcción iconográfica de la siguiente pieza, otorgada como premio a un fotógrafo de nombre H. Wormleighton, en 1905. 

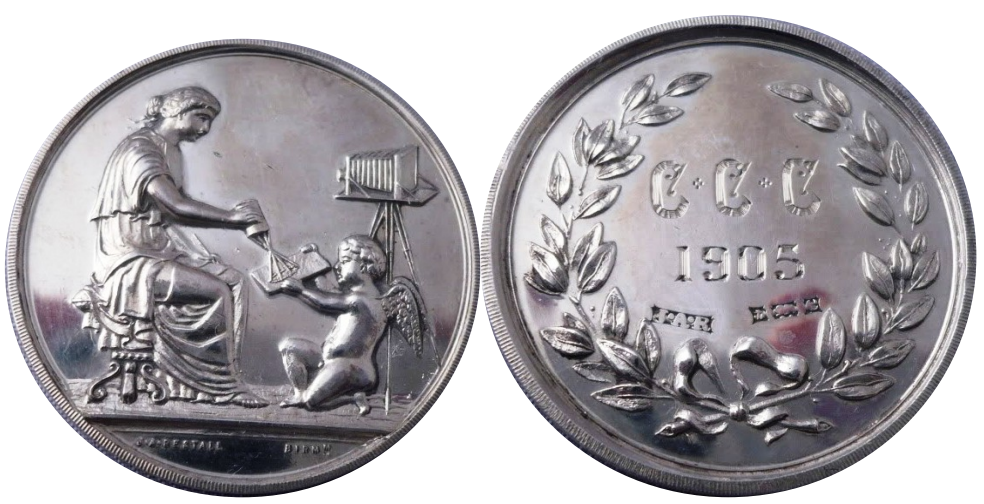

C.C.C. - H.WORMLEIGHTON (1905), plata, 32 mm. J.J. Restall, Birmingham. Colección del autor

Una descripción pre-iconográfica del anverso de esta medalla nos presenta, a la izquierda, una figura femenina sentada, sosteniendo con su mano derecha una especie de prisma, con el cual proyecta unos rayos de luz sobre una placa sostenida por una figura infantil alada. En el fondo, a la derecha, una cámara fotográfica, apuntando hacia la izquierda. La lectura iconográfica convencional apunta hacia una escena claramente alegórica, una figura femenina seguramente mitológica o inmortal, dado a que está acompañada por un pequeño ángel o Cupido. El tercer nivel de análisis, el del signo cultural o iconológico, señala nuevamente hacia la exaltación de la reproducción de las imágenes a través de la escritura de la luz, o la fotografía (o utilizando el término acuñado por el propio Niepce, la "heliografía", o escritura de la luz solar).

Como hemos señalado, uno de los elementos discursivos fundamentales de la primera etapa de existencia del proceso fotográfico fue la noción de su supremacía mimética, esto es, su capacidad absoluta, como proceso ópticoquímico-mecánico autónomo, de reproducir con total fidelidad y perfección al referente externo. El denominado discurso de la "fotografía-espejo" es uno de los de mayor prevalencia a través del tiempo, el cual, como ya sabemos, llevó a consecuencias peligrosas al asumirse que la similitud o realismo analógico de lo fotografiado era garante de su veracidad. Este axioma, no necesariamente cierto, de que todo lo que la fotografía captura y refleja no puede ser otra cosa que lo real y verdadero, se presenta representado en un 
signo icónico muy peculiar, frecuentemente presente en la iconografía de la medallística fotográfica: el espejo de mano.
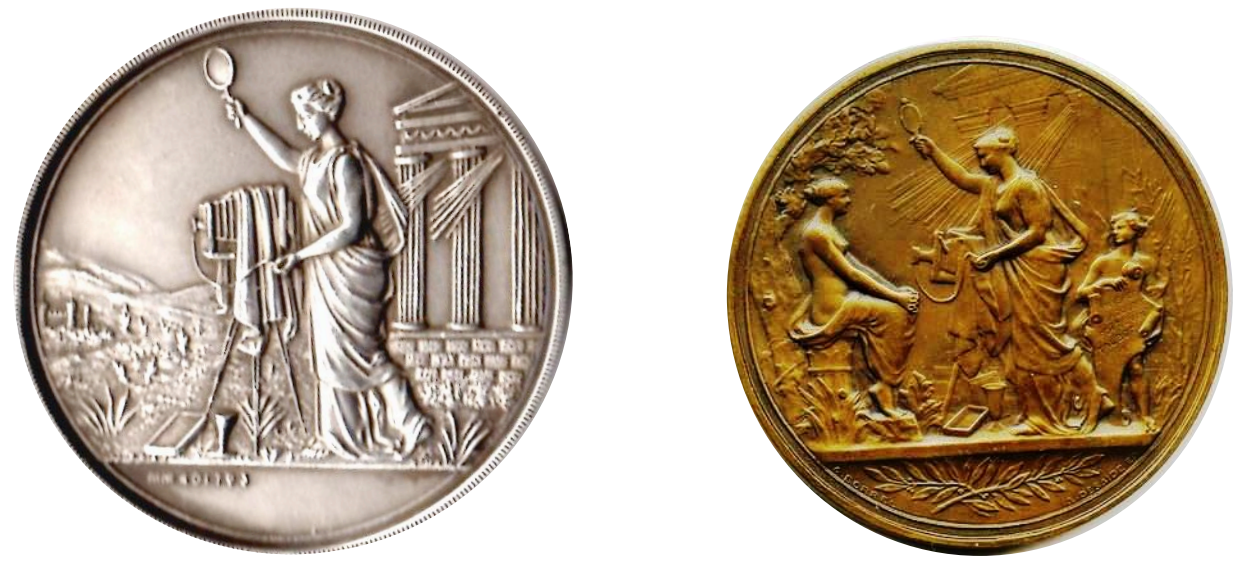

IZQUIERDA: PORTSMOUTH CAMERA CLUB (1922), bronce laminado en plata, 45mm; DERECHA: SOCIETÉ DES PRODUITS AS DE TRÉFLES (ca. 1930), bronce, 45mm. Colección del autor.

Es claro que las dos medallas que se muestran sobre estas líneas tienen un origen común, por no decir que alguno de los artistas copió el concepto básico de su colega. La medalla en plata del PORTSMOUTH CAMERA CLUB (izquierda) es de origen inglés, mientras que la de la derecha (SOCIETÉ DES PRODUITS AS DE TRÉFLES) es francesa. Aunque esta última es mucho más elaborada y contiene otros elementos (como por ejemplo, el ángel de la derecha sosteniendo un letrero que exalta los nombres de Niépce, Daguerre y Talbot, precursores de la invención fotográfica), el elemento central en ambas consiste de una figura alegórica femenina al centro, manejando una cámara fotográfica (una apuntando al paisaje, la otra a una modelo sentada), ambas sosteniendo en alto un espejo de mano en su mano derecha. Desde tiempos antiguos el espejo de mano ha constituido un símbolo dual de vanidad, así como de reflejo de la realidad, esto es, de la verdad. En este caso el mensaje es obvio. La cámara captura y refleja lo real y verdadero. No está sujeta a interpretaciones subjetivas del artista o del ser humano. La luz aparece nuevamente como elemento de la naturaleza, en los rayos que se proyectan desde el templo al fondo de la escena (de hecho, en la medalla francesa, el friso del templo presenta la inscripción en latín "LUMINIS", o luz, exaltando la propiedad casi divina del proceso fotográfico). El signo del 
espejo aparece nuevamente en la siguiente medalla de la LEICESTERSHIRE PHOTOGRAPHIC SOCIETY, fechada en 1900.
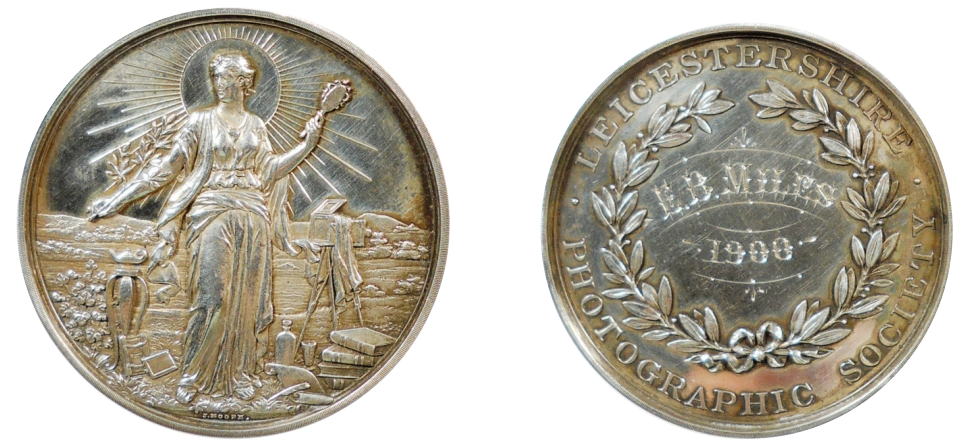

LEICESTERSHIRE PHOTOGRAPHIC SOCIETY (1900), plata, 45mm. Colección del autor

Nuevamente una figura femenina alegórica, de pie, ocupa el centro de la composición, con un elaborado paisaje rural al fondo cuyo horizonte sirve de punto de corte para dividir la escena en dos mitades iguales. Al igual que en otras instancias (como en el caso examinado previamente de la medalla de Rochester Photographic Club), un efecto de halo resalta el rostro de la mujer, conformado por el disco solar y sus rayos de luz, en este caso de forma mucho más preponderante, dominando visualmente toda la parte superior de la composición. Este signo comunica nuevamente unos atributos metafísicos, significando a la figura femenina como un símbolo más allá de lo terrenal. De nuevo, una alegoría combinada de luz y naturaleza, elementos consubstanciales al proceso fotográfico. La mujer porta en su mano izquierda el espejo de mano, reflejo de la verdad, y en su mano derecha una rama de olivo. Una cámara fotográfica se coloca en segundo plano, a la derecha, rodeada por libros, pergaminos y otros utensilios fotográficos. A la izquierda se destaca una lámpara de aceite, símbolo convencional de conocimiento y sabiduría. En su conjunto la composición exalta la fotografía como fuente de verdad y reflejo del mundo, y su lugar entre las artes y ciencias del saber humano.

No pasaron muchos años desde su invención para que la fotografía fuese exaltada por sus defensores como un arte en sí mismo. Su capacidad mimética llevó a la fotografía a ganar incluso su entrada a las exhibiciones y las paredes de los museos en competencia abierta con la pintura - 
competencia que ganó eventualmente amparada por su afinidad directa con las corrientes y mentalidades positivistas de la época. Siempre hubo críticos acérrimos al nuevo medio, entre los cuales el poeta Baudelaire (Dubois, 1994: 22) se destacará por sus ataques despiadados, no ya contra la nueva invención por sí misma, sino más bien contra la actitud de las masas ante la perfección ilusoria que ésta prometía:

"En materia de pintura y de estatuaria, el Credo actual de la gente del mundo, sobre todo en Francia (y no creo que nadie se atreva a afirmar lo contrario) es este: «Creo en la naturaleza y sólo en la naturaleza... Así la actividad que nos proporcionará un resultado idéntico a la naturaleza sería el arte absoluto». Un dios vengador ha satisfecho los deseos de esta multitud. Daguerre fue su Mesías. Y entonces ella se dice: "Puesto que la fotografía nos da todas las garantías deseables de exactitud (iy se lo creen, los insensatos!), el arte es la fotografía». A partir de ese momento, la sociedad inmunda se precipitó, como un único Narciso, para contemplar su imagen trivial sobre el metal. Una locura, un fanatismo extraordinario se apoderó de todos esos nuevos adoradores del sol".

Superando toda crítica, la supremacía de la fotografía como medio de representación analógica -aún por sobre la pintura- no solo prevaleció sino que se arraigó en la mentalidad decimonónica. Contemporáneo de Baudelaire, Hippolyte Taine sentenciará: “...la fotografía es el arte que, sobre una superficie plana, con líneas y tonos, imita con perfección y ninguna posibilidad de error la forma de objeto que debe reproducir" (Dubois, 1994: 23).

Esta exaltación de la fotografía como expresión artística, e incluso como un arte superior a la pintura, se refleja en la iconografía de muchas medallas fotográficas, como los ejemplos que mostramos a continuación. Obsérvese cómo se resalta el lugar de la cámara fotográfica entre el caballete, el lienzo, la paleta de colores y demás utensilios comúnmente relacionados al arte pictórico. 

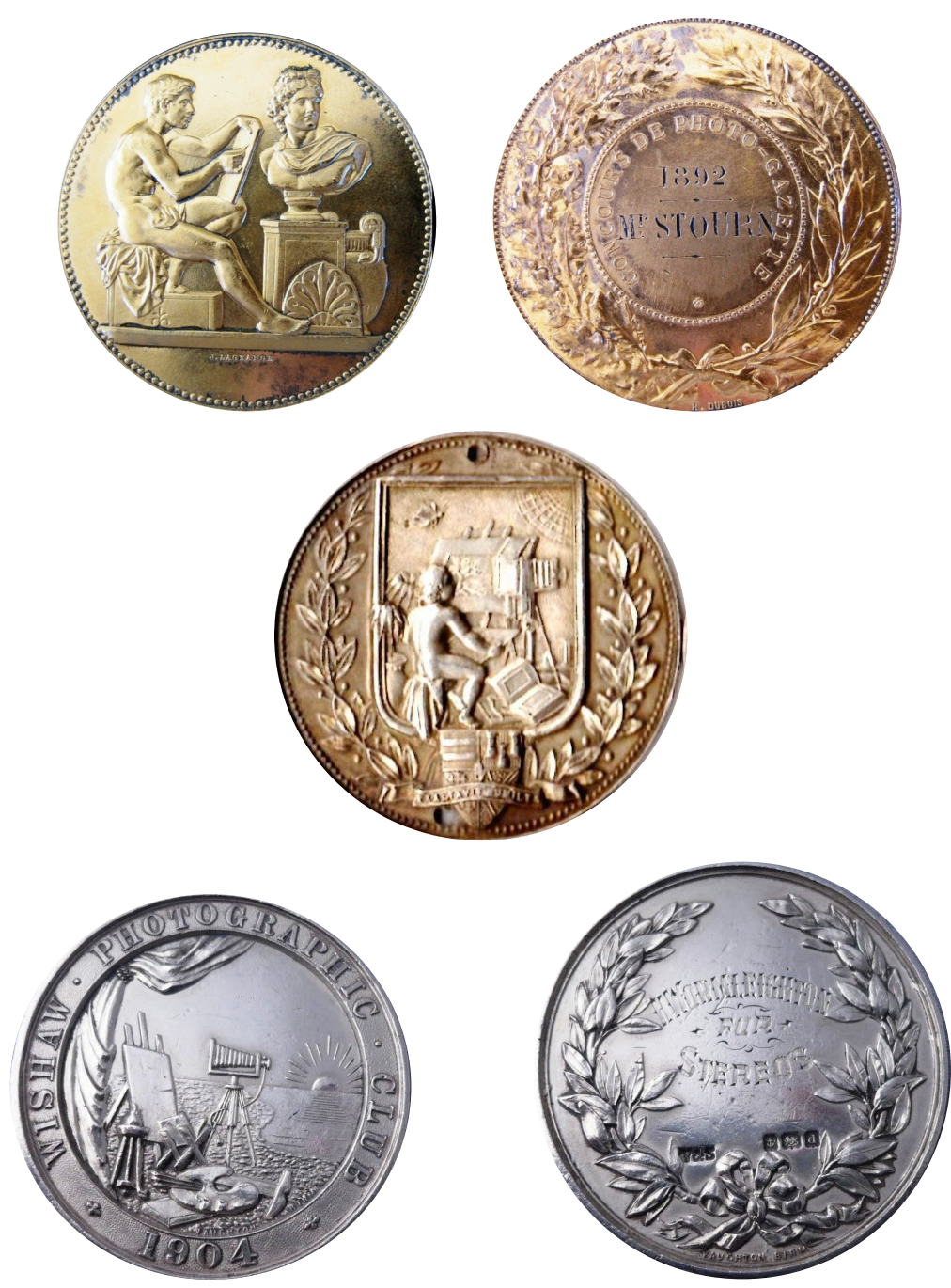

Arriba: CONCOURSE DE PHOTO-GAZETTE (Francia, 1892); Centro: ASTON PHOTOGRAPHIC SOCIETY (1904);

Abajo: WISHAW PHOTOGRAPHIC CLUB (1904). Colección del autor
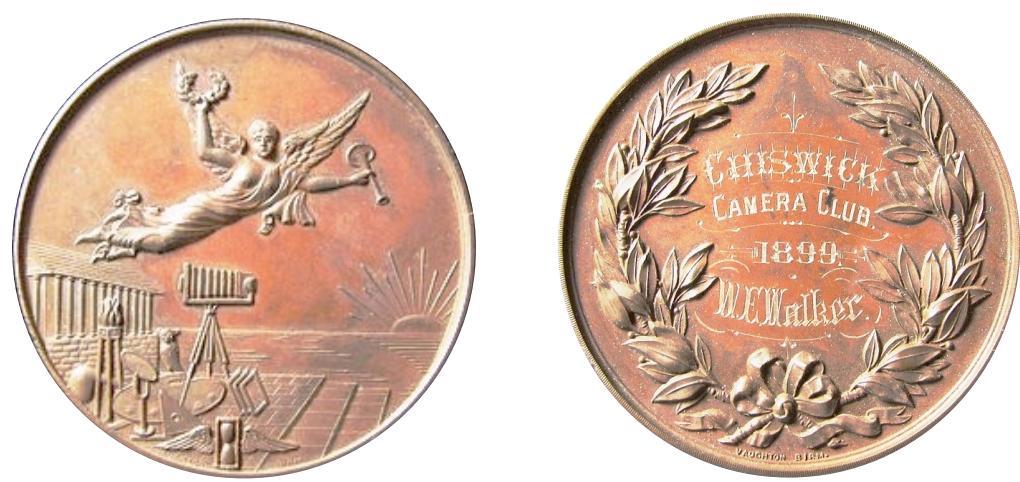

CHISWICK CAMERA CLUB (1899), bronce 45mm. Colección del autor 
La construcción iconográfica de la medalla anterior (WISHAW PHOTOGRAPHIC CLUB, 1904), se asemeja mucho a la de la medalla mostrada arriba del CHISWICK CAMERA CLUB, otorgada a W.E. Walker en 1899. La cámara colocada al centro de la composición, mirando en dirección de un sol naciente, y rodeada por implementos artísticos (la paleta de colores) y científicos (frasco de laboratorio, a la izquierda), trasmite nuevamente el mensaje de supremacía de la fotografía entre las artes y las ciencias. No obstante, se añaden en esta medalla otros elementos iconográficos importantes. El más evidente, ocupando la totalidad del campo superior, es una figura femenina alada, portando una trompeta y una corona de laureles. La composición recuerda inevitablemente la Victoria alada o diosa Nike, frecuente en muchas antiguas monedas griegas, y la cual denotaba un mensaje de laudo y homenaje a los vencedores. En este caso es claro que el vencedor, por sobre otras expresiones artísticas y científicas, es el medio fotográfico. El templo al fondo complementa el entorno alegórico, mientras se añaden otros elementos simbólicos interesantes, como lo son el búho (símbolo de sabiduría) y el espejo (reflejo de la verdad, ya explicado). Justo en el exergo, ocupando el primer plano en la composición visual, aparece un reloj de arena alado, símbolo masónico del "tempus fugit" (el tiempo vuela), concepto sobre la brevedad de la vida y la temporalidad del ser humano, el cual data desde tiempos ancestrales.

Uno de los elementos más predominantes en la mentalidad de las sociedades europeas de fines del siglo XIX lo fue el discurso o paradigma del progreso. Según explica Alvarez Curbelo (2001), producto del positivismo y la ilustración dieciochesca, el ideario del progreso está atado al desarrollo científico y al paradigma mental del crecimiento y mejoramiento lineal hacia etapas cada vez más altas de civilización. La narrativa del progreso incremental y, en gran medida, inexorable, estuvo acendrada sobre las invenciones, el desarrollo tecnológico, el crecimiento poblacional y la expansión geográfica, sobre todo de los viejos y nuevos imperios (Álvarez Curbelo, 2001: 34-35). 
Dentro de este contexto, la invención de la fotografía ocupó un lugar preponderante en su acepción de innovación tecnológica al servicio del progreso, así como de las necesidades del explorador, el etnógrafo, el antropólogo, el naturalista y demás representantes de las nuevas autoridades imperiales en su afán por conocer, inventariar y controlar los nuevos territorios. Como explican Schwartz y Ryan (2003: 2-3), el mundo, hecho más familiar y accesible a través de la fotografía, estaba cambiando rápidamente bajo la bandera del progreso. La industrialización, la expansión urbana y las innovaciones en la transportación y las comunicaciones, en conjunto con la aparición de la clase media y el nacimiento del concepto moderno de la nación-estado, alteraron profundamente las mentalidades intelectuales, sociales y políticas de las sociedades metropolitanas y de sus posesiones.

En una época en que el ferrocarril y el telégrafo hacían al mundo más accesible físicamente, la fotografía lo hizo accesible visual y conceptualmente. Por estas razones, la cámara fotográfica, sus nuevas tecnologías, el proceso fotográfico mismo, así como la exhibición de sus productos visuales, ocuparon un lugar de privilegio en las múltiples ferias y exposiciones universales que proliferaron desde mediados y finales de siglo XIX a través de las principales capitales europeas y occidentales. Dicha presencia se denota con preeminencia en el reverso de la medalla conmemorativa de la exposición universal de París de 1900, diseñada por el escultor Georges Lemaire.
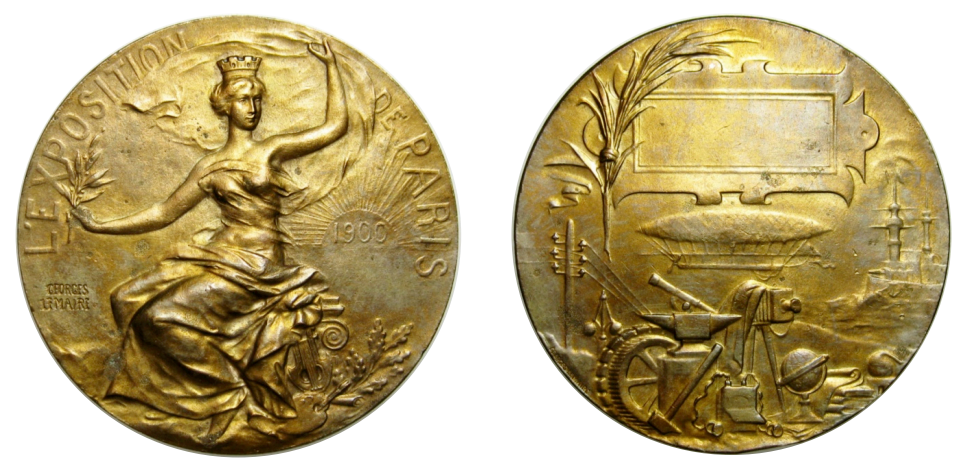

EXPOSICION UNIVERSAL DE PARÍS (1900), Georges Lemaire, plata 53mm. Colección del autor 
En ésta, la cámara fotográfica ocupa una posición céntrica, privilegiada, en un conjunto iconográfico que claramente busca resaltar las diversas innovaciones tecnológicas de fines de siglo, las cuales representan la esencia del progreso científico y la expansión geográfica de la época: a la izquierda, las líneas telegráficas; arriba, un dirigible representando los inicios de la transportación aérea; a la derecha, el barco de vapor, y en la parte inferior, elementos de la industrialización, las ciencias y la exploración. La fotografía se constituye en la única de las invenciones que puede servir de documentación y eslabón a todas las demás dimensiones del saber y el quehacer humano.

La última pieza en nuestra muestra resume este pensamiento y el rol de la invención fotográfica en el proceso civilizador y progresista. Se trata de otra medalla de premiación otorgada al fotógrafo inglés $\mathrm{H}$. Wormleighton, esta vez por el Isle of Wight Photographic Society (ca. 1905). La descripción preiconográfica del anverso nos presenta una figura femenina de pie, al centro, cargando un caduceo con su mano izquierda, mientras con la derecha coloca una corona de laureles sobre una cámara fotográfica. En el fondo, a la izquierda, una choza de paja. A la derecha, un caballete, un yunque, una rueda hidráulica y una paleta de colores. Al identificar los significados convencionales primarios, vemos en el caduceo el símbolo del comercio (asociado al antiguo dios Mercurio), la choza puede representar primitivismo, y el conjunto de la derecha, las artes, ciencias y la industrialización. Claramente, la mirada, el gesto y todo el movimiento de la figura están enfocados en la cámara fotográfica, la cual es exaltada al ser coronada con laureles de triunfo. Aunque puede simplificarse la interpretación del conjunto, reduciéndolo a una mera alusión a la premiación en un concurso o exhibición fotográfica, no es forzada una interpretación cultural alusiva al progreso, a la evolución de la civilización -desde el atraso primitivo, hasta los avances económicos, científicos y artísticos- dentro de los cuales la fotografía ocupa un lugar reconocido en su rol de instrumento cuasi científico de documentación. 

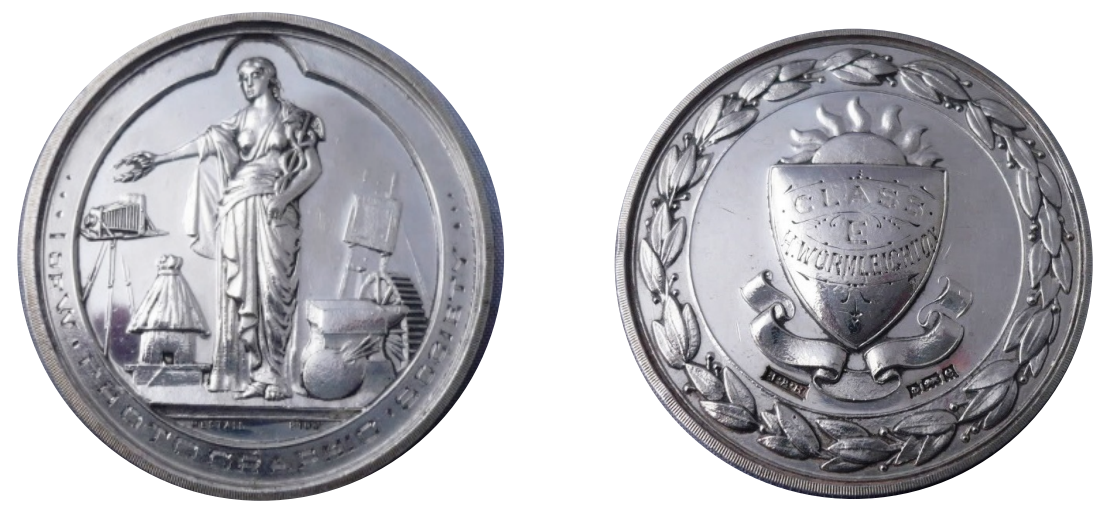

I. of W. PHOTOGRAPHIC SOCIETY (ca. 1905), plata 45mm. Colección del autor

\section{Conclusión}

El análisis iconográfico de este grupo representativo de medallas, creadas durante el apogeo de la invención fotográfica, es ilustrativo de la forma en que los elementos y signos visuales sirven para comunicar - muchas veces de manera velada y metafórica - las convenciones, discursos y esquemas valorativos que conforman la visión de mundo de un grupo social, en un momento histórico dado. Transcurridas unas pocas décadas desde su creación, hacia finales del siglo XIX, la fotografía ocupaba ya un sitial privilegiado en la mentalidad decimonónica, habiendo establecido todo un nuevo referente y estándar en lo relativo a los procesos de representación y reproducción de las imágenes visuales. No solo se trataba de un impresionante desarrollo tecnológico, aliado del progreso científico y económico, sino más aún, como señala Giséle Freund (1976), constituyó un medio "democratizador" del conocimiento, y uno de los signos del avance de las nueva clases burguesas, las cuales veían en la reproducción fotográfica de sus retratos familiares el equivalente de los retratos comisionados a los grandes pintores por las clases nobles y privilegiadas del pasado. Pero mucho más profundo que estos elementos progresistas, la fotografía estableció un nuevo paradigma mental sobre lo real y lo verosímil en la comunicación visual, un discurso que impuso a las imágenes fotográficas la carga ineludible 
de la evidencia (Tagg, 1988), de la prueba y documentación - más que de lo meramente análogo, de lo verdadero.

Con el devenir del tiempo y los avances tecnológicos, el impacto de la fotografía permeó cada rincón de nuestra cotidianidad. La fotografía de prensa, las fotos estereoscópicas, las tarjetas postales, el álbum familiar, el advenimiento de las imágenes en movimiento (el cinematógrafo), la televisión, hasta las actuales imágenes digitales. No importa el nivel de sofisticación tecnológica al que hayamos llegado, o al que podamos llegar, es claro que todo el andamiaje de nuestra sociedad mediática contemporánea descansa en la propuesta inicial de la imagen fotográfica. Y aunque hayamos perdido en gran medida el sentido de fascinación que ella provocó en sus albores, como muy bien expresó Sontag (2006), “irredimiblemente persistimos aún en la caverna platónica, deleitados, por costumbre ancestral, con meras imágenes de la verdad”.

\section{Referencias bibliográficas}

ALVAREZ CURBELO, Silvia (2001). Un país del provenir: El afán de modernidad en Puerto Rico (siglo XIX). San Juan: Ediciones Callejón.

JOLY, Martine (1994). La imagen fija. Buenos Aires: Editorial La Mirada.

BARTHES, Roland (1961). "Le message photographique". En: Communications, Núm. 1, París.

BAUDELAIRE, Charles (1859). "Le public moderne et la photographie”, en Salón de 1859.

BAURET, Gabriel (1992). De la fotografía. Buenos Aires: Editorial La Marca

BURZIO, Humberto (1958). Diccionario de la moneda hispanoamericana. Tomo II. Santiago de Chile.

DUBOIS, Philippe (1994). El acto fotográfico: De la representación a la recepción. BuenosAires: Paidós Comunicación.

FREUND, Giséle (1976). La fotografía como documento social. Barcelona: Editorial Gustavo Gili,

PANOFSKY, Erwin (1955, 1980). El significado de las artes visuales. Alianza Forma.

SCHWARTZ, J.; Ryan, J. (eds.) (2003). Picturing Place: Photography and the Geographical Imagination. Londres: I.B. Taurus.

SONTAG, Susan. Sobre la fotografía. Editorial Alfaguara, Buenos Aires, 2006. 
TAGG, John (1988). The Burden of Representation: Essays on Photographies and Histories. Londres: McMillian Education Ltd. 